Artigo original

Hegemonia - Revista Eletrônica de Relações Internacionais do Centro Universitário Unieuro

ISSN: $1809-1261$

UNIEURO, Brasília, número 14, 2014, pp. 4-24.

Recebido em: $21 / 5 / 2014$

Avaliado em:4/6/2014

Aprovado em: $8 / 7 / 2014$

\title{
Utopia Hobbesiana: Conflito no Estado Brasileiro
}

José Renato Maia Thé ${ }^{1}$ e Lidia de Oliveira Xavier $^{2}$

Resumo: Este artigo procura analisar se o Estado brasileiro faz cumprir os desígnios estipulados por Thomas Hobbes, descritos em sua obra Leviatã (2006). Nesse sentido, o arcabouço que norteou o engendramento de solução encontrada pelo autor na acomodação das relações entre os indivíduos, aplicada no caso brasileiro, constitui medida eficiente para que a problemática promovida pela tríade competição, desconfiança e glória seja resolvida? É possível, dada a premissa do medo, apaziguar as relações conflituosas? A hipótese sugerida neste artigo é de que, no Brasil, o Estado reúne condições incipientes para garantir a paz entre seus indivíduos; mas, ao contrário, o Estado promove a tríade de forma que o conflito ganha contornos maiores, quando os cidadãos passam a regular as suas relações, por conta própria, com outros indivíduos.

Palavras-chave: Estado; Violência; Conflito; Paz.

Abstract: This article discusses the conflict promoted by the State of Brazil from the point of view of Thomas Hobbes, in which fear or the inability to manage the relationships, based on the triad: competition, distrust and glory, is a basic premise of the shares in Brazilian society. In this sense, the framework that guided the solution found by the author in the accommodation of relations between individuals, applied to the Brazilian case, it is efficient for the issue presented by the triad is solved? It is possible, starting the premise of fear, appease the conflicting relationships that triad contain? The hypothesis suggested in this paper, in Brazil, is the State has incipient conditions to ensure

Especialista em Gestão Pública pela UDF Centro Universitário e Mestre em Ciência Política pelo Centro Universitário Unieuro.

Doutora em História pela Universidade de Brasília e Coordenadora do Curso de Mestrado em Ciência Política do Centro Universitário Unieuro. 


\section{Artigo original}

Hegemonia - Revista Eletrônica de Relações Internacionais do Centro Universitário Unieuro

ISSN: $1809-1261$

UNIEURO, Brasília, número 14, 2014, pp. 4-24.

peace among his citizens; but on the contrary, the State contributes for the triad gets larger, when citizens come to regulate their relations on their own with other citizens.

Keywords: State; Violence; Conflict; Peace. 
Artigo original

Hegemonia - Revista Eletrônica de Relações Internacionais do Centro Universitário Unieuro

ISSN: $1809-1261$

UNIEURO, Brasília, número 14, 2014, pp. 4-24.

Introdução

O presente artigo tem como objetivo discutir se o Estado brasileiro faz cumprir os desígnios estipulados por Thomas Hobbes (1999) quando da publicação de sua célebre obra Leviatã (1999). Para tanto, contextualiza historicamente o tema da segurança, analisa se esta é observada no cotidiano do povo brasileiro de modo a permiti-lo o direito de ir e vir e, testa a proposta de Hobbes no Estado brasileiro. Parte da hipótese de que o Estado brasileiro vive um diapasão entre o ideário hobbesiano e a insegurança vivida nas relações de seus cidadãos, procurando responder a seguinte questão: vive-se uma completa falta de segurança, ao tempo em que o Estado dá uma falsa sensação de tê-la?

Assim, utiliza a cronologia hobessiana, a partir da cessão de soberania do Homem a favor de um ente - Estado -, para regular suas relações de forma a defendê-lo e protegê-lo contra ameaças de seus semelhantes. Nesse sentido passa a indagar, se de fato o Estado pôs fim à violência a partir da cessão de parte da soberania (liberdade) do indivíduo; se a concepção hobbesiana soluciona o problema da defesa e proteção aos súditos, compreendido aqui como cidadãos do Estado e; se em terras brasileiras, 0 Estado age de forma a proteger seus cidadãos ou se serve como agente de violência.

Para tanto, recorre ao método dedutivo/formal de observação empírica, enquadrada historicamente, com revisão bibliográfica baseadas em textos nos campos da Sociologia e Ciência Política e o estrutura em quatro pontos: o primeiro mostrar a dicotomia entre paz e conflito, ao tempo em que pretende conceituar paz; o segundo demonstra panorama geral do Estado idealizado por Hobbes (2006) - sob o ponto de vista da segurança e da violência; o terceiro contextualiza historicamente a evolução do pensamento hobbesiano no Brasil e, o quarto discute a hipótese acima apresentada; e por seu turno.

1 A Dicotomia entre conflito e paz - conceituação

Os movimentos históricos ocorridos no velho continente e que ultrapassaram suas fronteiras reverberaram em grande parte do mundo. Esses 
Artigo original

Hegemonia - Revista Eletrônica de Relações Internacionais do Centro Universitário Unieuro

ISSN: $1809-1261$

UNIEURO, Brasília, número 14, 2014, pp. 4-24.

movimentos resgatam a historiografia ${ }^{3}$ em torno dos processos de construção da paz na tentativa de mostrar que os interesses dos Estados variam de acordo com inúmeros aspectos. A definição utilizada para designar 'Estados' possui a mesma estrutura utilizada por Gozzi (1983), na qual, 1) a estrutura formal do sistema jurídico garante as liberdades fundamentais com a aplicação da lei por parte de juízes independentes; 2) a estrutura material observa a liberdade de concorrência no mercado, reconhecendo o comércio aos sujeitos da propriedade; 3) estrutura social, onde as questões sociais e políticas são respeitadas, inclusive aquelas em que garantam as reformas pelas quais a classe trabalhadora se organiza (em sindicatos); e estrutura política, com a separação e distribuições de poder.

Assim, o desafio que cada Estado faz para determinar o conceito de paz é orientado por sua autodeterminação, também entendido por soberania. 0 problema que o conceito de paz passa a enfrentar é o paradoxo no qual está imerso, pois, ao mesmo tempo, é ilimitado, orientado pela idiossincrasia e pela teleologia que cada um possui; e limitado pelas relações que mantém alémfronteiras. Em outras palavras, os aspectos endógenos e exógenos orientam a maneira que cada Estado age e interage com seus cidadãos e com outros Estados, podendo receber inúmeras contradições entre ambos os lados.

Outro ponto de inflexão diz respeito à definição do conceito de paz imerso ou incluso no campo semântico de guerra (também entendido como violência). Tange, portanto, a compreensão humana do conceito de violência mais próxima da natureza humana no modelo hobbesiano. Nesse sentido, paz parece estar em ponto fora do limite da razão humana. Assim, a questão é dada pelo fato de que somente há paz em função da violência, sendo condição necessária para que haja paz; ou ainda, sem violência não há paz. A estrutura argumentativa carrega o mesmo raciocínio de que somente há saúde se houver doença, somente há riqueza se houver pobreza. Esse tipo de estrutura remete à reflexão de negação do fato por oposição a ele, ou ainda, ratificação de um fato também por oposição. Mas também se deve observar outra questão - 0

O termo empregado possui, além do sentido de Ciência da História, o registro deste e o estabelecimento das relações feitas pela própria humanidade na construção das relações sociais. 
Artigo original

Hegemonia - Revista Eletrônica de Relações Internacionais do Centro Universitário Unieuro

ISSN: $1809-1261$

UNIEURO, Brasília, número 14, 2014, pp. 4-24.

processo semântico, que adensa a discussão; pois, em torno dos conceitos e dos contra-conceitos há sinais, significados que variam de acordo com as experiências individuais.

$O$ retrato realista disso reside no maniqueísmo entre conflito e paz; assim, parece haver algo pelo qual os Estados repousam seus objetivos, que Ihes imputam a certeza de seus propósitos. Esse 'algo' está intrinsecamente associado às 'verdades' e 'determinações' pelas quais os Estados são motivados. Dessa forma, tentam submeter outros Estados que não possuem tais verdades ou que delas discordam, quase sempre pelas vias do conflito. Se isso for observado no campo externo, o que se dirá da relação entre o Estado e seus cidadãos?

Embora a linha seja tênue entre as 'verdades' e as 'determinações', vale a pena colocá-las em campos separados para que não se tenha a indução de confundi-las quando da tentativa de conceituação de paz. Essa breve digressão é fundamental para que o 'conceito' não seja imposto, aceito ou mesmo se tenha a pretensão de esgotá-lo. Caso contrário, estar-se-ia ocorrendo em mesmo equívoco das guerras, ao tentar conceituá-la por meio de 'verdades' e 'determinações'. Ao contrário, quer-se apenas fomentar a reflexão sobre o Estado hobbesiano.

O conceito relacionado ao Estado beligerante é amplamente entendido e pacificado no campo 'lógico', sendo, portanto, entendido como luta, briga, disputa. A enciclopédia Einaudi (1985) vai além, associa o conceito de paz ao de guerra, pois que:

[...] aprece, como denominador comum entre guerra e a paz (entendida como ausência de guerra), tanto o desenvolver da acção (sic) humana em geral (ou, numa palavra, da vida), quanto à forma como tal acção (sic) contribui para modificar as condições existentes num dado momento. (ANCONA, apud EINAUDI, 1985: 353). (grifo nosso).

Vê-se que o conceito de paz não é positivamente constituído, mas pertence ao campo semântico do conceito anterior; em outras palavras, paz é ausência de conflito. Enquanto o primeiro [conflito/guerra/violência] está configurado no campo real. Paz, portanto, contém forte campo metafísico. 
Artigo original

Hegemonia - Revista Eletrônica de Relações Internacionais do Centro Universitário Unieuro

ISSN: $1809-1261$

UNIEURO, Brasília, número 14, 2014, pp. 4-24.

Algumas definições de paz deságuam em estado de espírito, retratado em dogmas religiosos.

A aderência ao que se afirma pode ser encontrada nas palavras de Tomás de Aquino quando trata da quies ab exteriotibus motibus. (In: ARENDT, 2010:18). Esse estado de ausência contemplativa, próprio da reflexão sobre algo, leva a conclusões no campo das ideias, podendo ser estruturadas de forma sistêmica e/ou cartesiana. Interessante são as passagens de Aristóteles em Política, e de Tomás de Aquino em Suma Teológica, respectivamente, acerca do tema por Hannah Arendt:

[...] tal como a guerra ocorre em vista da paz, também todo tipo de atividade, mesmo processo de mero pensamento, deve culminar na absoluta quietude da contemplação. Todo movimento, os movimentos do corpo e da alma, bem como do discurso e do raciocínio devem cessar diante da verdade. (ARENDT, 2010:18).

A construção do pensamento de Aristóteles, ao comparar a quietude da contemplação opostamente contrária à agitação, ratificada por Tomás de Aquino, pressupõe o 'estado de violência' completamente dissociado do 'estado de paz'.

O maniqueísmo entre os dois 'estados' em Arendt sucede ao que Hobbes (1999) intitulou em sua obra Leviatã a 'guerra de todos contra todos'. A expressão utilizada pelo autor, embora tenha como pano de fundo o medo ${ }^{4}$, justifica-se ao se analisar o texto e o contexto à sua época, facilitando o entendimento da expressão cunhada pelo autor.

Se se observado o 'estado de guerra' na condição humana, como sugerido por Hobbes (1999), qual, afinal, a passagem deste estado a outro de paz? O próprio Hobbes tenta determinar o receituário: uma associação na qual cada indivíduo cede parte de sua liberdade (soberania individual na capacidade de fazer ou deixar de fazer algo) a um ente que acolha a cessão de todas as

O medo está presente, segundo Renato Janine Ribeiro (1999), em quase toda a vida de Hobbes. Em sua obra Leviatã, Hobbes aponta de forma definitiva que o medo é o sustentáculo para concepção de Estado. 


\section{Artigo original}

Hegemonia - Revista Eletrônica de Relações Internacionais do Centro Universitário Unieuro

ISSN: $1809-1261$

UNIEURO, Brasília, número 14, 2014, pp. 4-24.

liberdades dos indivíduos. A competência deste ente seria proteger cada indivíduo dos demais indivíduos que lhe quisessem fazer qualquer tipo de ' $m a{ }^{\prime \prime}$, assim o medo ou a iminência da guerra cessaria e daria lugar à paz.

Não obstante a construção da paz por meio da cessão da soberania individual em prol da coletiva, faz-se necessário relatar que isso não é observado em plano factual no que diz respeito às relações entre os Estados, pois necessitaria de outro ente superior a esses, uma associação confederativa, talvez. Esse entendimento norteou o pensamento de outro autor, o Abade Saint-Pierre (2003), que também notou tal fragilidade e propôs outro tipo de associação, quando da obra Le Projet de Paix Perpétuelle. Assim como Hobbes, Saint-Pierre imaginou a cessão de parte da soberania, desta vez pelos Estados, para compor outro entre Supra-Estatal. Tal ideia fez alguns analistas contemporâneos e modernos atribuírem os ideais do Abade às bases da atual União Europeia.

A tentativa de conceituar paz, portanto, ao que parece, necessita, à primeira vista, haver medo permanente de guerra, a sensação de possibilidade desta, ou ainda, recente trauma por ela causado para que o propósito da paz seja alcançado. Tal entendimento é baseado, como estabelecido por Hobbes, pelo medo de que outro indivíduo/Estado avoque para si a soberania 'vontades' e 'determinantes' - anteriormente cedidas.

Se por um lado o recorte dado a paz pela cessão da soberania entre indivíduos de terminado Estado está razoavelmente bem definida, ainda que seja possível observar movimentos em torno do mundo que ameacem o ideal hobbesiano, não se pode dizer o mesmo quando as relações envolvem os fatores de produção, antagonismo étnicos, dominância bélica, por exemplo. Nesse ponto, a relação volta-se para os fatores internos de cada Estado. Para Belligni, o conceito de hegemonia, no uso das relações entre Estados, é entendido como:

Observa-se mais uma vez que o "mal" é condição necessária para existência do "bem" e vice-versa; uma visão maniqueísta novamente. 
Artigo original

Hegemonia - Revista Eletrônica de Relações Internacionais do Centro Universitário Unieuro

ISSN: $1809-1261$

UNIEURO, Brasília, número 14, 2014, pp. 4-24.

[...] direção suprema, usada para indicar o poder absoluto [...]. A potência hegemônica exerce sobre as demais uma preeminência não só militar, como também frequentemente econômica e cultural, inspirando-Ihes e condicionando-Ihes as opções, tanto por força do seu prestígio como em virtude do seu elevado potencial de intimidação e coerção [...]. (BELLIGNI, 1983: 579).

Outro autor que trabalhou o tema foi Immanuel Kant. Para este a paz "não podia ser instituída ou assegurada sem um contrato dos povos entre si." (KANT, 2010: 40). O ponto comum entre Kant e Saint-Pierre reside na crença em uma paz perpétua pela razão, cuja força é maior que o poder. Observa-se que o emprego desse tema diz respeito à capacidade de um ator exercer influência sobre outros atores do sistema internacional.

Nesse sentido, é interessante observar o que Michel Foucault (2010), em Em Defesa da Sociedade, quando propõe uma análise das relações de poder, sendo o aspecto belicoso o princípio de inteligibilidade e de análise do poder político. Observa a necessidade de exercício do "poder mediante a produção da verdade". Aqui, a construção do texto de Foucault observa que é de crucial importância a produção da 'verdade' para o exercício do poder. E nesse contexto, qualquer que seja a intenção, basta que se produza a 'verdade' e que ela seja 'determinada' para que a sociedade de um Estado qualquer apoie o seu líder em suas ações na imposição dessa verdade a outros Estados e até mesmo a seus cidadãos.

A partir disso, o Estado pode gerar violência ou pelo menos intimidar outro quando da tentativa de guerrear em lado oposto àquele. No campo interno, o poder coercitivo obriga o cidadão a cumprir os mandamentos impostos pelo Estado, de forma que a relação é e, talvez, sempre o será topdown.

2 Panorama geral do Estado idealizado por Hobbes

O Estado idealizado por Hobbes, bem como seus escritos estão localizados no contexto da Guerra Civil na Inglaterra, o que Ihe deu uma concepção a cerca da natureza humana do homem em suas relações sociais e interpessoais. 
Artigo original

Hegemonia - Revista Eletrônica de Relações Internacionais do Centro Universitário Unieuro

ISSN: $1809-1261$

UNIEURO, Brasília, número 14, 2014, pp. 4-24.

O texto e contexto extraído da obra Leviatã é o retrato da fragilidade na qual se encontrava a Inglaterra de seu tempo, o que, talvez, tenha-o feito pensar na forma e meios pelos quais o estado de natureza se manifesta.

Hobbes (1999) afirma que todos nascem iguais quanto à faculdade do corpo e do espírito e que o agir de cada um se dá pela prudência. A prudência observada pelo autor leva o indivíduo a fazer suposições quanto ao agir do outro, o qual, por sua vez, também as faz em relação a terceiros. Essas suposições de todas as partes resultam no ataque de um para com o outro e vice-versa, ou para vencê-lo, ou para evitar um possível ataque. Em larga escala a violência se generaliza, o que torna o convívio impossível.

Hobbes era um contratualista e por isso defendia a paz por meio de um 'contrato' entre todos a fim de estabelecer regras de convívio social. Esse contrato seria responsável por criar/montar um ente que estivesse acima das relações entre os indivíduos e que fosse constituído de poder ilimitado, reunido em braço forte - na representação de um soberano monárquico.

O funcionamento desse contrato estaria alicerçado pela concessão de parte da soberania de cada indivíduo - retratado no poder de matar, por exemplo - a esse ente superior. Em troca, esse ente além de regular as relações entre o todo, também, e principalmente, garantira a proteção contra o todo.

O estado de natureza do homem para Hobbes, portanto, é o de beligerância, o que o levou a afirmar que o "Homem é lobo do próprio homem." (HOBBES, 1999), como se lê:

[...] (da) igualdade quanto à capacidade deriva a igualdade quanto á esperança de atingirmos nossos fins. Portanto, se dois homens desejam a mesma coisa, ao mesmo tempo, que impossível ela ser gozada por ambos, eles tornam-se inimigos. (HOBBES, 1999: 110).

Essa perspectiva na realidade hobbesiana, sem ilusões, conduz o autor a fazer a célebre dedução em relação ao estado de natureza de todo homem, podendo este ter direito a tudo:

O direito de natureza, a que os autores geralmente chamam jus naturalle, é a liberdade que cada homem possui de usar seu próprio poder, da maneira que quiser, para a preservação de sua própria 
Artigo original

Hegemonia - Revista Eletrônica de Relações Internacionais do Centro Universitário Unieuro

ISSN: $1809-1261$

UNIEURO, Brasília, número 14, 2014, pp. 4-24.

natureza, ou seja, de sua vida; e consequentemente de fazer tudo aquilo que seu próprio julgamento e razão Ihe indiquem como meios adequados a esse fim. (HOBBES, 1999: 115).

As razões pelas quais Hobbes justifica seu pensamento reside no que seria a natureza do homem, e, nas causas que o levam a agir: a discórdia, a competição e a glória. A discórdia que levaria os homens a se tornarem senhores de outros homens, mulheres, filhos, bens. A competição que levaria os homens a defenderem os mesmos pontos relatados pela discórdia. E por fim, a glória que levaria os homens a serem reconhecidos por ninharias, tais como: sorriso, palavras, gestos, reconhecimentos.

Interessante notar que para Hobbes (1999) tanto a discórdia quanto a competição são concomitantes, o que difere da glória. Ajunta-se o fato de que o estado beligerante constitui a natureza humana até que estes tenham um poder capaz de mantê-los em paz, em respeito. Eis a defesa estipulada por Hobbes (1999) pela Teoria Contratualista. Tal teoria é resultante do pensamento iniciado no século XVII no qual a cessão de parte da soberania individual de cada homem em prol de um ente que fosse capaz de harmonizar todos os homens.

A fim de fundamentar seu raciocínio o autor traz a discussão e define o que é a lei de natureza e como esta se relaciona com a razão. Em suas palavras:

Uma lei de natureza (lex naturalis) é um preceito ou regra geral, estabelecido pela razão, mediante o qual se proíbe a um homem fazer tudo o que possa destruir sua vida ou privá-lo dos meios necessários para a preservar, ou omitir aquilo que pense melhor contribuir para a preservar. (HOBBES, 1999: 115).

Hobbes (1999) faz o relato acima em função da concepção da condição do homem - guerra de todos contra todos -, tendo cada qual o seu propósito, baseado em suas razões, sobretudo, no que diz respeito à sua existência, podendo valer-se de qualquer instrumento para preservar a sua vida. Entretanto, há uma regra geral no pensamento do autor, que utiliza como argumento: "que todo homem deve esforçar-se pela paz, na medida em que 
Artigo original

Hegemonia - Revista Eletrônica de Relações Internacionais do Centro Universitário Unieuro

ISSN: $1809-1261$

UNIEURO, Brasília, número 14, 2014, pp. 4-24.

tenha esperança de consegui-la, e caso não a consiga pode procurar e usar todas as ajudas e vantagens da guerra." (HOBBES, 1999).

Interessante observar que o objetivo do homem em Hobbes é a paz e que se não for possível tê-la, deverá ser utilizado mecanismo beligerante para obtê-la. O resultado é um segundo argumento do autor:

[...] (quando) um homem concorde, quando outros também o façam, e na medida em que tal considere necessário para a paz e para a defesa de si mesmo, em renunciar a seu direito a todas as coisas, contentando-se, em relação aos outros homens, com a mesma liberdade que aos outros homens permite em relação a si mesmo. (HOBBES, 1999: 116).

Tal argumento possui o pano de fundo em sua crença católica, pois suscita a lei do Evangelho: "Faça aos outros o que queres que vos façam." Vêse o esforço do pensador em fundamentar os argumentos no campo jurídico, na existência de um Estado capaz de controlar os ímpetos da discórdia, da competição e da glória, por meio de um contrato.

O entendimento do Estado idealizado por Hobbes (1999) se dá quando a cessão de parte da liberdade, retratada na violência individual na defesa da lei de natureza, é transferida ao ente maior, observada que a cessão é amplamente assimilada pelo surgimento do ente por meio do contrato, ou seja, o Estado idealizado é poderoso e utiliza da violência para se justificar, mantendo todos os homens sob seu julgo.

3 Contexto histórico e a evolução do pensamento hobbesiano no Brasil

Os Estados não são uma invenção acabada, vivem em constante avanço e por vezes retrocessos, mas longe de algo que se pode rotular como perto da perfeição. Nesse contexto, o Estado brasileiro assimilou preceitos estipulados pelos clássicos da Ciência Política. Aqui, os postulados de Hobbes são questionados pela falta constante de segurança, o que resulta o homem ser lobo do próprio homem literalmente. A presença do medo tem cada vez mais demonstrada suas facetas em relatos feitos pelos meios de comunicação que estampam a quase inexistência da presença do Estado como agente de 


\section{Artigo original}

Hegemonia - Revista Eletrônica de Relações Internacionais do Centro Universitário Unieuro

ISSN: $1809-1261$

UNIEURO, Brasília, número 14, 2014, pp. 4-24.

pacificação em determinados casos. Ao contrário, o sentimento que se tem é de completa inação, ineficiência e descaso no trato da proteção ao cidadão, com ênfase aos desprovidos de recursos financeiros.

Refere-se não apenas na violência direta encontrada nas ruas, com expoente em roubos, assaltos, estupros, agressões, assassinatos, mas também pela corrupção, pela impunidade, que dá a sensação de se passar incólume pelas 'barbas da justiça.'

Esse pequeno panorama do cotidiano no Brasil deságua em uma corrida às avessas do Estado idealizado por Thomas Hobbes, a ausência do papel que the rege - proteção a seus cidadãos e garantia de convivência pacífica. A associação do que fora dito possui aderência ao apelo à experiência pessoal de cada um, provocado por Hobbes:

Que seja portanto (sic) ele a considerar-se a si mesmo, que quando empreender uma viagem se arma e procura ir bem acompanhado; que quando vai dormir fecha suas portas; que mesmo quando está em casa tranca seus cofres; e isto mesmo sabendo que existem leis e funcionários públicos armados, prontos a vingar qualquer injuria que Ihe possa ser feita. (HOBBES, 1999: 112).

O julgo parece ser claro, quando o Estado não reúne condições suficientes para garantir a proteção à integridade física e à propriedade privada, o cidadão teria o direito de fazê-lo por sua conta. Em grande medida é exatamente isso o que ocorre com a corrida à segurança particular - instalação de sistemas de câmeras de segurança, cercas elétricas, contratos de seguro dentre outros.

Evidentemente, isso acontece em todo o mundo. Entretanto, um aspecto que inabilita o Estado brasileiro a reproduzir as condições ideais estipuladas pelo pensador não advém da cessão da liberdade, mas sim o uso da violência como mecanismo de dominação utilizada pelo Estado e como estratégia de sobrevivência por parte de população, sobretudo, menos favorecida. 
Artigo original

Hegemonia - Revista Eletrônica de Relações Internacionais do Centro Universitário Unieuro

ISSN: $1809-1261$

UNIEURO, Brasília, número 14, 2014, pp. 4-24.

Segundo Rubens George Oliven ${ }^{6}$ (2010), a questão da violência no Brasil deve ser analisada a partir da construção da sociedade brasileira em bases violentas, embora sistematicamente negada a nível ideológico: "No Brasil haveria uma índole pacífica supostamente herdada dos portugueses, que teria sabido tão generosamente promover sua suave mistura de raças, criando uma sociedade harmônica." (OLIVEN, 2010: 6).

Entretanto, a história nos revela outros aspectos que reforça 0 pensamento do autor. $O$ advento da República, que ajudou a forjar a identidade brasileira no final do século XIX, até certo ponto baseada em transição mansa, contrasta com a violência utilizada na repressão a movimentos populares que antecederam esses eventos, tais como: Quilombo dos Palmares, Cabanada, Balaiada, Revolta da Chibata, Guerra dos Farrapos.

As repressões violentas tinham como objetivo a manutenção do status quo, retratado na dominação hegemônica do Estado. Tais ações recebiam como resposta mais protestos e um posicionamento social, por parte das classes menos favorecidas, diametralmente oposta às classes dominantes. Essa condição gerada deste a chegada dos portugueses, alimentado por uma cultura baseada na corrupção e por meio de produção escravocrata, gerou distanciamentos que perdura até hoje.

Do ponto de vista dos menos favorecidos, Oliven (2013) retrata uma reação de confronto à posição da elite brasileira. A cultura da malandragem, em termos discriminatórios, arraiga-se de forma definitiva nos morros cariocas com o surgimento das favelas ${ }^{7}$ e a revoltas populares, como a da vacina ${ }^{8}$, são

É professor titular de da e membro da de onde foi presidente em 2000-2002. Recebeu o seu na (University of London, London School of Economics and Political Science) é professor visitante da, e da de Paris.

A origem do termo em português do Brasil favela surge no episódio histórico conhecido por Guerra de Canudos, A cidadela de Canudos foi construída junto a alguns morros, entre eles o Morro da Favela, assim batizado em virtude da planta Cnidoscolus quercifolius (popularmente chamada de favela) que encobria a região. Alguns dos soldados que foram para a guerra, ao regressarem ao Rio de Janeiro em 1987, deixaram de receber o soldo, instandose em construções provisórias erigidas sobre o Morro da Providência. O local passou então a ser designado popularmente Morro da Favela, em referência à 'favela' original. O nome favela ficou conhecido e na década de 1920, as habitações improvisadas, sem infraestrutura, que ocupavam os morros passaram a ser chamadas de favelas. 
Artigo original

Hegemonia - Revista Eletrônica de Relações Internacionais do Centro Universitário Unieuro

ISSN: $1809-1261$

UNIEURO, Brasília, número 14, 2014, pp. 4-24.

pontos determinísticos para a sua compreensão. Portanto, a cultura brasileira da esperteza, do 'jeitinho brasileiro', da malandragem, neste contexto, surgem em oposição aos ditames das altas classes.

Vê-se a dicotomia estabelecida pela violência entre os estrados sociais como o fiel da balança, podendo esta pender em situações específicas para um ou para outro lado. De modo latente, o distanciamento entre os estratos sociais constitui motivo fático de geração de violência e de medo. Guardadas as devidas proporções, o mesmo se deu na Inglaterra de Hobbes, com esponte na Guerra Civil que the moldou as reflexões sobre a guerra de todos contra todos.

Interessante notar como os estudiosos no campo social - inclui-se aqui a economia - comungam em afirmar que a redução do distanciamento entre as classes sociais dar-se-á com uma melhor distribuição de renda, pois isso é fator de acomodação social e, portanto, redução na violência. Entretanto, a distribuição de renda observada do ponto de vista isolado, não será suficiente para resolver o problema da violência.

Se as disparidades econômicas entre os países ricos e pobres em torno do globo são observadas, o mesmo quadro é encontrado no plano interno. As diferenças no Brasil apontam para uma persistente concentração de renda. Em terras brasileiras, $10 \%$ da população detêm $41,9 \%$ da renda, enquanto outro $40 \%$ da mesma população detêm $13,3 \%$ da renda (IBGE, 2013). As mudanças promovidas pelos governos parecem ainda não surtir efeito de forma a fazer o Brasil dar um salto de qualidade no que diz respeito à distribuição de renda.

A concentração de renda suscita a precariedade das relações entre os cidadãos no Brasil. Porém, essa é apenas uma variável das 'equação' do

Para erradicar a varíola, o sanitarista Oswaldo Cruz convenceu o Congresso a aprovar a Lei da Vacina Obrigatória (31 de outubro de 1904), que permitia que brigadas sanitárias, acompanhadas por policiais, entrassem nas casas para aplicar a vacina à força. Entretanto, a revolta foi contundente, a população armou-se e transformou o centro do Rio de Janeiro em campo de batalha: era a rejeição à vacina contra varíola. 
Artigo original

Hegemonia - Revista Eletrônica de Relações Internacionais do Centro Universitário Unieuro

ISSN: $1809-1261$

UNIEURO, Brasília, número 14, 2014, pp. 4-24.

pensamento hobbesiano, outros pontos como a geração de renda e, principalmente, a educação das classes menos favorecidas constituem importantes fatores de mitigação da violência no Estado brasileiro.

\section{Discussão hipotética}

A provocação acerca da hipótese contida no texto da introdução desse artigo pretendia lançar luz sobre o assunto ao tempo em que deixa a critério do leitor as possibilidades de atuação do tema. Entretanto, a questão balizar a respeito da releitura de Hobbes em tempos atuais imprime desafios grandiosos pela complexidade do assunto e pelo alargamento do campo epistemológico acumulando deste a época dos pensamentos do autor.

A questão em torno da violência e da possibilidade de o cidadão avocar para si a liberdade (entendida também por soberania) cedida em prol da formação de um ente superior que the rege as relações frente a outros cidadãos, volta à tona. Ao que tudo indica a realidade não é a segurança stricto sensu -, mas uma falsa sensação desta.

Essa sensação no Estado brasileiro está em consonância a outros ao redor do globo? Eles [outros Estados] agem de forma a promover uma completa segurança? As análises sobre esse prisma, tendo por base a natureza humana conduz as resposta a um 'não' que ecoa retumbante, o que torna a conclusão sobre o assunto não definitiva, pois cada agente, cada indivíduo faz julgo sobre a sensação de segurança. Nesse sentido, deixa-se, portanto, que cada qual faça suas reflexões acerca do tema e alargue o objeto de pesquisa.

Outro aspecto a ser abordado na hipótese é a suposta retomada da liberdade concedida ao ente que regularia as relações internas - o Estado. Aqui a posição é determinística, a cessão jamais poderá ser retomada, de forma a não haver mais o Estado como fora forjado e como se encontra nos dias atuais, no entanto, se pode pensar em aprimoramentos, composições e outros políticos. Assim, a opção por formação de Estado é caminho inexorável. O desafio, portanto, é o aperfeiçoamento das relações com a participação dos cidadãos exercendo força sobre o 'Leviatã', numa espécie de 'contramão' hobbesiana. 
Artigo original

Hegemonia - Revista Eletrônica de Relações Internacionais do Centro Universitário Unieuro

ISSN: $1809-1261$

UNIEURO, Brasília, número 14, 2014, pp. 4-24.

As contribuições de Thomas Hobbes no campo da Ciência Política e da Filosofia são inegáveis. Suas teorias contribuíam para o enriquecimento do saber e da concepção de Estado e sociedade, que continuam sendo objetos de estudo e pesquisa. $O$ pensamento hobbesiano, do ponto de vista filosófico, traz à tona a ontologia do ser no tocante ao estado de natureza do homem. Hobbes procura analisar a essência do homem em seus relacionamentos, com o objetivo de engendrar mecanismos constituintes das interações humanas. Porém, o faz sob o pano de fundo a Guerra Civil inglesa. Tal incidente deu-lhe contornos determinantes na observação do homem. Afirmava que o comportamento de outros levariam a ação, e que quase necessariamente a contra ação seria conflituosa, sobretudo, se o objeto de disputa for de interesse de ambos os indivíduos ao mesmo tempo, de forma que todos, na busca por suas ações, guerreariam contra todos.

O Leviatã idealizado por Hobbes poria um fim nas disputas e conduziria todos por ele administrado à paz. O Estado regularia as ações dos indivíduos protegendo-os e garantido a paz. 0 artigo traz a temática em relação à paz consubstanciada na presença do Estado, que regularia as ações entre os indivíduos e protegeria uns dos outros. Procurou-se estabelecer a ausência das premissas básicas estipuladas por Hobbes no Estado brasileiro em afirmar a utopia do autor aliado à tímida atuação do Brasil na regulação e proteção dos seus cidadãos no cotidiano.

Outro aspecto observado foi a dicotomia estabelecida entre os conceitos de conflito e de paz, sendo este último hipotético e campo semântico do primeiro, motivo pelo qual não existe conceito estruturado de paz dissociado ao de guerra. Essa imprecisão se daria em função do estado de natureza que o homem possuiria, pois para Hobbes o homem age por medo e, guiado por ações que visem a se proteger de outros homens, Ihe conferindo caráter belicoso/violento.

O ponto de inflexão quando se olha o posicionamento do Brasil contextualizado em Hobbes de maneira generalizada reside na relação de uma única via - a do cidadão na cessão de parte de sua soberania -, sem que o Estado Ihe garanta de forma ampla a segurança como contrapartida. A consequência disso é a busca, por parte da população, de auto-proteção, retratada em soluções como sistemas de segurança, vigilância e outros dispositivos que garantam sua segurança e consequente paz. 


\section{Artigo original}

Hegemonia - Revista Eletrônica de Relações Internacionais do Centro Universitário Unieuro

ISSN: 1809-1261

UNIEURO, Brasília, número 14, 2014, pp. 4-24.

Nesse sentido, qual seria a condição de garantia à proteção dos cidadãos? Chega-se, portanto, a uma retórica no que diz respeito à igualdade em sentido amplo: o Brasil caminhará para o ideário hobbesiano quando as necessidades básicas entre os indivíduos forem observadas, de forma a reduzir as distâncias dos extratos no Brasil? Dessa forma, o quadro em que a sociedade brasileira está imersa traz o desafio que somente ela poderá promover na direção de saída da falsa sensação de segurança para um verdadeiro estado hobbesiano. 
Artigo original

Hegemonia - Revista Eletrônica de Relações Internacionais do Centro Universitário Unieuro

ISSN: $1809-1261$

UNIEURO, Brasília, número 14, 2014, pp. 4-24.

\section{REFERÊNCIAS}

Livros

AQUINO, Tomás. Suma Teológica. Araras: Odeon, 1934.

ARENDT, Hannah. A Condição Humana. Tradução de Roberto Raposo. Rio de Janeiro: Forense Universitária, 2010.

ARISTÓTELES. Política. $3^{\circ}$ ed. Tradução de Mário da Gama Kury. Brasília: Editora Universidade de Brasília - UNB, 1997.

BOBBIO, Norberto. MATTEUCCI, Nicola. PASQUINO, Gianfranco. Dicionário de Política. Tradução: Carmen C. Varrialle, Gaetano Lo Mônaco, João Ferreira, Luís Guerreiro Pinto Cacais e Renzo Dini. 3 ed. Brasília: Editora Universidade de Brasília,1983.

FERREIRA FILHO, Manoel. Direitos Humanos Fundamentais. 13a Ed. São Paulo: Saraiva, 2011.

FOUCAULT, Michel. Em Defesa da Sociedade. São Paulo: Martins Fontes, 2005. . Nascimento da biopolítica. São Paulo: Martins Fontes, 2008.

HOBBES, Thomas. Leviatã. Tradução: João Paulo Monteiro e Maria Beatriz Nizza da Silva. São Paulo: Nova Cultural, 1999.

KANT, Immanuel. A paz perpétua. Tradução: Artur Mourão. Covilhã: Lusofia, 2008.

OLIVEN, Ruben. Violência e Cultura no Brasil. Rio de Janeiro: Centro Edelstein de Pesquisa Sociais, 2010.

PIERRE, Abbé de Saint. Projeto para tornar perpétua a paz na Europa. Tradução de Sérgio Duarte. Brasília: Editora Universidade de Brasília, 2003. 
Artigo original

Hegemonia - Revista Eletrônica de Relações Internacionais do Centro Universitário Unieuro

ISSN: $1809-1261$

UNIEURO, Brasília, número 14, 2014, pp. 4-24.

PLATÃO. República. Tradução de Enrico Corvisieri. Rio de Janeiro: Best Seller, 2002.

RIBEIRO, Renato Janine. Ao leitor sem medo: Hobbes escrevendo contra o seu tempo. 2 Ed. Belo Horizonte: UFMG, 1999.

\section{Artigos}

ANCONA, Clemente. 'Guerra', In Enciclopédia Einaudi - volume 14: Estado Guerra. Lisboa: Imprensa Nacional/Casa da Moeda, 1985, pp. 348-71.

MANIN, Bernard. 'Paz'. In: Enciclopédia Einaudi - vol. 5: Antropos-Homem. Lisboa: Imprensa Nacional/Casa da Moeda, 1985, pp. 273-95.

BELLIGNI, Silvano. 'Hegemonia'. In: BOBBIO, Norberto; MATTEUCCI, Nicola; PASQUINO, Gianfranco. Dicionário de Política - vol. 1: Hegemonia. Brasília: Unb, 1983, pp. 579-81.

GOZZI, Gustavo. 'Estado'. In: BOBBIO, Norberto; MATTEUCCI, Nicola; PASQUINO, Gianfranco. Dicionário de Política - vol. 1: Estado Contemporâneo. Brasília: Unb, 1983, pp. 401-09.

HABITAT, ONU. Estado de las Ciudades de América Latina y el Caribe 2012 Rumbo a uma nueva tansición urbana. [S.I.:s.n], 2012. Disponível em: $<$ http://estaticog1.globo.com/2012/08/21/Estado-de-las-Ciudades-de-AmericaLatina-y-el-Caribe-2012.pdf>. Acesso em: 22 mai. 2014.

INSTITUDO BRASILEIRO DE ESTATISTICA E GEOGRAFIA - IBGE, [S.I.:s.n], [2013]. Disponível em: <http://www.ibge.gov.br/home/>. Acesso em: 21 abr. 2013.

LAFER, Celso. A internacionalização dos direitos humanos. São Paulo: Manole, 2005. Disponível em: <http://bdjur.stj.gov.br>. Acesso em: 22 mai. 2012.

SYMONIDES, Janusz. Direitos Humanos: novas dimensões e desafios. Brasília: UNESCO, Secretaria Especial de Direitos Humanos, 2003. Disponível em: <http://unesdoc.unesco.org/images/0013/001340/134027por.pdf>. Acesso em 17 abr. 2014. 
Artigo original

Hegemonia - Revista Eletrônica de Relações Internacionais do Centro Universitário Unieuro

ISSN: 1809-1261

UNIEURO, Brasília, número 14, 2014, pp. 4-24. 